\title{
Evaluation of Sulphate Resistance \& Effects of Glass Powder as A Supllementary Cementitious Material on the Performance of High Strength Mortar
}

\author{
Er. Hardeep Singh \\ Research Scholar, Dept. of Civil Engineering. \\ Indo-global group of Colleges. \\ Abhipur, Mohali, India
}

\author{
Er. Kiran Talwar \\ Assistant Prof, Dept. of Civil Engineering \\ Indo-global group of Colleges \\ Abhipur, Mohali. India
}

\begin{abstract}
Concrete, is the most widely used engineering material in construction. Since around 11 billion tons of concrete is used each year all over the world, considerable amount of cement is required for its production. This results in high production of carbon dioxide which is one of the main reasons of global warming. Therefore, in the last few years, there is a growing interest in using waste pozzolanic admixtures as a supplementary cementations' material. Using these kinds of admixtures as a part of cement replacement reduces the air pollution, cost and also enhances some properties of mortars and concretes. Among the other waste natural pozzolans, glass powder becomes important due to its high content of silica, availability and cost. These motivate lots of researchers to evaluate the effects of glass powder as a cement replacement material. In this study, effects of three different types (colors) of glass powders with different quantities used as cement replacement on the workability and mechanical properties of high strength mortars were evaluated. For this purpose, the flow table test for workability, flexural and compressive strength tests, modulus of elasticity measurement, rapid chloride test for permeability were performed to determine the effects of water binder ratio on high strength mortars performance. Moreover, the effect of curing temperature on the performance of high strength mortars modified with glass powders was also investigated. Finally, comparison is done between the results of control, silica fume and glass powder specimens. It is important to note that glass powder addition as a pozzolanic material has a considerable Influence on compressive strength and permeability at low water binder ratio specimens under high curing temperature.
\end{abstract}

Keywords: Glass powder, curing temperature, water-binder ratio, workability, compressive and flexural strength, modulus of elasticity, permeability.

\section{INTRODUCTION}

Concrete and mortar are the most widely used materials in construction all over the world. In the last few years, a growing appeal in using waste materials as a replacement of part of aggregates and/or cement in mortar and concrete productions has been seen. Using these kinds of objects as a part of cement replacement not only provides some benefits to its microstructure and performance, but also it gives an opportunity to reduce the amount of cement used and hence decrease the final cost of concrete manufacturing. From environmental point of view, this leads to reduction in the release of $\mathrm{CO} 2$ in the atmosphere, which is one of the main reasons for global warming (Siddique, Waste Materials and By-products in Concrete, 2008).Around the world, million tons of waste glasses are dumped into the nature every year. In 2005, around 13 million tons of waste glass was produced and dumped only in America. Also, other sources showed that the United Kingdom produces 1.3 million tons of waste glass every year (Ansari Ismail, 2015).The glass is a non-crystalline structure and it contains up to $70 \%$ of silica oxide, which can help to produce more $\mathrm{C}-\mathrm{S}-\mathrm{H}$ phases in cement pastes, mortars and therefore concrete. On the other hand, widespread availability of glass makes it cheaper and easier to produce when compared to other pozzolanic admixtures. This reality motivated lots of researchers to investigate the possibility of using waste glass as a natural pozzolan and also study the effects of using waste glass in concrete, as a cement replacement. Since 1970s, many researchers studied the effect of glass used as cement or aggregate replacement in concrete (Johnston, 1974), (Limbachiya, 2009), (Meyer, 1999).Sulfates are naturally present in significant amounts in soil, ground- water, industrial effluents, and wastes from chemical and mining industries, and sea water. Many Portland cement concrete (PCC) structures, which are either constructed in the previously mentioned regions or in close proximity to such sources, have shown severe premature deteriorations (Kalousek et al. 1972; Vladimir 1987). Sulfates present internally in concrete due to the use of sulfate- rich aggregates, cement containing excess gypsum and sulfate bear- ing water, can also cause deteriorations; however, appropriate screening of ingredients and test procedures before concrete production can avoid such internal sulfate attack (Chengsheng et al. 1988; Yan et al. 1997). Of the different sulfates such as sodium, magnesium, calcium, and ammonium sulfates that cause deterioration in concrete, the first two have been found to be the most common ones, with the magnesium sulfates causing more destruction than any others (Cohen and Bentur 1988; Bonen and Cohen The sulfate resistance in concrete can be provided by using port- land cements that are low in their $\mathrm{C} 3 \mathrm{~A}$ content, such as ASTM C150 (ASTM 2012a) Type II cement

(Moderate sulfate resistance) or Type V cement (high sulfate resistance). In situations in which such sulfate- 
resistant portland cements are not readily available, ordinary Portland cement can be used along with pozzolans such as fly ash, silica fume, slag, or metakaolin at appropriate cement replacement levels to minimize deteriorations due to sulfate attack. However, the sulfate resistance of the blend depends greatly on the chemistry of the pozzolan used and its replacement level. In particular, the ability of the pozzolan to reduce permeability of matrix is essential to improving the sulfate resistance (Mindess et al. 2003). One research showed that waste glass powder finer than $45 \mu \mathrm{m}$ has improved the durability of concrete (Schwarz N, 2008). Shi showed that fine glass powder with the fineness of $582 \mathrm{~m}^{2} / \mathrm{kg}$ has high pozzolanic activity index and as the fineness of waste glass increased, the pozzolanic strength activity index increased (Shi C, 2005). ShaoY. Showed that, grounded waste glass with a particle size less than $38 \mu \mathrm{m}$ had high pozzolanic activity index (Shao Y L. T., 2000). As a general conclusion; higher compressive strength, lower expansion of alkali-silica reaction and higher strength activity could be the results of finer particles of waste ground glass powder. Idir also showed fine that ground glass with a specific surface area (more than $180 \mathrm{~m} 2 / \mathrm{kg}$ ) can reduce mortars expansion due to exposure to alkali-silica reaction. Mortars containing fine ground glass, more than the specific surface area of $180 \mathrm{~m} 2 / \mathrm{kg}$, which is exposed to alkali-silica reaction, had lower expansion when compared to mortars without this admixture (Idir R, 2010).

Key words: glass powder, Portland cement concrete, Ammonium sulfates, ASTM, sulfate resistance, fly ash, Metakolin

\section{LITERATURE REVIEW}

Aboshama, et al (2016). Waste glass powder: Another source of cement replacement is produced from waste glasses and called waste glass powder. Waste glass is said to have the desired chemical blend to use as a cementitious supplementary material in concrete due to its pozzolanic properties, and can improve hydration, mechanical properties, and the durability of mortars. However, to achieve this potential, the particles need to be graded to a micro size to be able to react with the cement particles. heating. Miguel Ángel Sanjuán, et al ( 2015) Nowadays, a combination of Portland cement and silica fume is being used to produce high performance or ultra-high performance concrete. This is made possible through the significant co-operation of Portland cement and silica fume. The physical and chemical effects of silica fume on the microstructure of hardened cement paste in mixtures leads to a higher strength, higher durability and lower permeability Ansari Ismail, et al (2015); near 13 million tons of waste glass was produced and disposed just in America. Also, other sources showed that the United Kingdom produces 1.3 million ton of waste glass every year One of the reasons is that it is important for glass production companies to produce high quality glass, which might be used as sheets or bottles. Therefore, there is a recommended proportion of raw material to produce glass to achieve this quality. Most of these instructions recommend at least $40 \%$ of glass cullet is good to be used as a part of raw materials for producing new glass in each batch. Nevertheless, they also recommend that cullet should not contain different colors of glass. In fact, if cullet contains even two different colors of glass, it becomes useless to produce new glass as it results in low quality glass with an undesired color. Jos Olivier,et al (2015). Gypsum mortar is the oldest mortar known to the mankind, first utilized by the Egyptians. Lime mortar has been said to be used since $4000 \mathrm{BC}$ in Egypt. It is produced by mixing of slaked lime, sand, and water. It is noticeable that more than 1900 famous ancient buildings all around the world are found to be made by using this kind of mortar. Compared to concrete, the amount of cement used in mortar is higher, and nowadays many researchers try to find a way to reduce the amount of cement used in concrete and mortar without decreasing the performances of cementitious mixtures. This is because of environmental reasons, as cement industries are the second biggest producers of $\mathrm{CO} 2$ in the world after iron and steel production with the total amount of $8 \%$ of total $\mathrm{CO} 2$ emission .Until today, one of the best ways to decrease the amount of cement in mixtures is to replace it partially with pozzolanic materials, which may be natural, artificial, or even waste products. Kumarappan, et al (2013) For fresh phase of concrete, some researchers demonstrated that replacement of glass powder up to $40 \%$ to cement with a particle size less than $300 \mu \mathrm{m}$ could increase the slump from $40 \mathrm{~mm}$ up to $160 \mathrm{~mm}$ ). Another research also showed that by increasing the amount of glass powder in concrete, the amount of slump is also increased. Dali et al (2012) Ground Granulated Blast-Furnace Slag (GGBS): it is a fine pozzolanic material, which contains alumina silicate and silicate, and is created by rapidly cooling the molten steel blast furnace slag with water. This pozzolan contains low amounts of crystal formation, is extremely cementitious and when the fineness of particles is similar to that of cement, hydration may also resemble that of Portland cement. Making concrete mixtures by replacing PC partially by slag helps improving its consistency in numerous ways. Chikhalikar et al (2012) also found an increase in the slump of concrete, using glass powder with particle size of $600 \mu \mathrm{m}$, up to $40 \%$ replacement of cement. Shayan et al (2006) investigated the effect of glass powder on workability of mortars. He concluded from his research that the increase in workability of mortar by replacing the glass powder is due to the surface structure of glass powder, which is crystal - like, and subsequently too little amount of water is absorbed by glass powder compared to cement particles.

\section{OBJECTIVE OF THE STUDY}

- $\quad$ Determining effects of three different types (colors) of glass powders with different quantities to cement replacement on workability and mechanical properties of high strength mortars produced by three different water binder ratios.

- Obtaining the best type and the optimum quantity of glass powder, which is the most suitable supplementary cementitious material for high strength mortars performance 
- Determining the effects of $w / b$ ratios on high strength mortars performance with different types and quantities of glass powders.

- Comparing the performances of high strength mortars with waste glass powders, silica fume and the control mortar specimens without any admixture.

- Studying the effect of the curing temperature on the performance of high strength mortars made by using glass powders.

- Evaluation of sulphate resistance factors on mortar and concrete.

- To compare the extent of deteriorations caused in glass powder mortars by the sodium and magnesium sulfate solutions.

\section{METHODOLOGY}

The mechanical properties and the permeability of high strength mortar modified by glass powder were investigated. In total, 72 batches of mortar with different proportions of ingredients were prepared. Effects of different types of glass powders with different proportions water-cement ratio and curing temperature on high strength mortars were investigated

\section{Definitions and proportions of materials used in mortars production}

Three different types of glass powder with particle sizes less than $63 \mu \mathrm{m}$ were replaced at two levels as $10 \%$ and $20 \%$ with cement, by weight. In addition, control mix without any admixtures, and one mix with $20 \%$ of silica fume, replacing cement were prepared for later comparisons. Types of glass powders were white glass powder (WGP), green glass powder (GGP), and brown glass powder (BGP) which are expected to have different effects on mechanical properties due to differences in ingredients as explained in chapter 2 . In addition, three different $w / b$ ratios as $0.35,0.40$ and 0.45 were selected and used in this study to investigate the effects of pozzolanic reaction of glass powders with differing $w / b$ ratios.

\section{Curing of Specimens}

After remolding the specimens, according to the curing temperature, they were put into normal water or were cured in high-temperature water for $48 \mathrm{hrs}$ after remolding. Specimens cured in normal room temperature were transferred to $22^{\circ} \mathrm{C}$ directly after remolding to cure in water up to the test day. Specimens subjected to high-temperature curing were put into high-temperature water curing tank $\left(55^{\circ} \mathrm{C}\right.$, or $80^{\circ} \mathrm{C}$ ) for the first $48 \mathrm{hrs}$ after remolding and then transferred to normal curing tank with $25^{\circ} \mathrm{C}$ until the day of testing.

\section{Fresh Mortar Workability Test}

Immediately after the mixing procedure was finished, a small amount of fresh mortar was collected to perform the flow table test for investigating the workability of fresh mortar for each batch. The mold was placed in the center, on the top of the flow table and was filled with two layers of mortar. Each layer was compacted with tamping rod, with 20 blows. 1 minute after the surface of mold became flat, the mold has been removed and 25 hits implied to the table in 15 seconds. The amount of propagation of fresh mortar on the table was measured at four different points on the diameter, and the average of 4 readings was reported. This test was performed according to ASTM C1437-15 standard test method. Standard ASTM C230-14 authenticated flow table Apparatus.

\section{Testing of Hardened Mortars \\ a) Flexural strength}

Tensile strength test provides a method for defining the flexural strength of mortars this test was performed according to ASTM C348-14. It was done with $40 \times 40 \times 160 \mathrm{~mm}$ prisms at $7 \mathrm{th}$, and 28 th day of curing, and 3 specimens were used in each test. It should be noticed that specimens were kept under water until the test date. Center Point loading method was used in flexure test on specimens. After recording the load measured by a machine, the following formula was used to calculate the flexural strength of mortars.

$S_{f}=0.0028 P$

Where: $\mathrm{P}=$ total maximum load $(\mathrm{N}) \mathrm{Sf}=$ flexural strength of specimen

\section{b) Compressive Strength}

This test was performed to investigate the amount of compressive strength of mortars at 7 and 28 days. Specimens, used for compressive strength test were broken prisms, which were used for flexural strength of mortars with diameters of $40 \mathrm{~mm}$ by $40 \mathrm{~mm}$ by $40 \mathrm{~mm}$ cubes, according to standard test method ASTM C349-14. In addition, each compressive strength test was done on three specimens and the average of three was reported as the compressive strength.

\section{c) Pozzolanic Activity Index}

Pozzolanic activity index cover methods for testing fly ash or other natural pozzolans to be used in mortars and concretes with Portland cement. The test was performed according to ASTM C311- 13. The proportion of raw material is listed in table 3.4. Portland cement type II, 42.5 was used in this test. Normal standard sand, and normal tap water was used to prepare the mixtures.

Table : 1 Effect of GP to pozzolanic activity index of mortar specimens

\begin{tabular}{lllll}
\hline Name & Cement $(g)$ & Sand $(g)$ & Water $(\mathrm{ml})$ & GP $(\mathrm{g}) /$ /type \\
\hline Control mix & 500 & 1375 & 242 & - \\
WGP-PC & 400 & 1375 & 242 & $100 \mathrm{~W}$ \\
BGP-PC & 400 & 1375 & 242 & $100 \mathrm{~B}$ \\
GGP-PC & 400 & 1375 & 242 & $100 \mathrm{G}$ \\
\hline
\end{tabular}


After preparation of specimens, according to ASTM C618, compressive strength of control and test specimens were tested at 28th day of curing under water with normal temperature, and then compared together as below

$$
\begin{aligned}
& \text { strength activity index with Portland cement }=\frac{A}{B} \times \\
& 100
\end{aligned}
$$

Where;

\section{A: compressive strength of test mixtures, $\mathrm{MPa}$}

$\mathrm{B}$ : compressive strength of control mixture, $\mathrm{MPa}$

\section{d) Rapid Chloride Permeability Test}

This test was performed to evaluate the effect of SF and BGP on resistance of mortar toward chloride ion penetration and the procedures satisfied the standard ASTM C1201. Rapid chloride permeability test was performed on the 56th day of curing of cylindrical specimens and was applied on 6 samples. This test includes observing total electrical current passing through $50-\mathrm{mm}$ pieces of cores, or cylinders with nominal diameter of 100mm during a period of 6hours. A potential variation of 60 $\mathrm{V}$ dc is provided at each end of the slices, with one end submerged in a solution of sodium chloride, and the other in a sodium hydroxide liquid After finishing each test, total charge passed from each sample is measured and compared with each other Resistance to Sulphate Attack Review of world practice shows that there are two current standards in operation; in the order in which they were developed they came from the American Society for Testing and Materials (ASTM) (Ref 7) followed in 1996 by Standards Australia (Ref 8). It must be noted immediately that both these tests relate to mortar and not concrete and therefore focus on the binder system. While the basic concepts of the two test methods are similar there are some differences. For example, while they are both expansion assessment tests, the sample configurations, sand types, mortar mix designs, and curing regimes are different, as are the performance assessment criteria. The overall objective with these tests is to assess the relative sulphate resistance of various binder options from traditional (basically low C3A content) sulphate resistant cements, to the various blended cements which are now found to have excellent properties in this particular aspect of concrete technology. At this point in time the Australian test is being widely used in rating various binder options although as provided for in the Preface to the test method some refinements of the procedure may be agreed after its first two years of operation. At the present time the key issue seems to be the duration of the test (presently 16 weeks), the permeability of the mortar, and the degree to which a longer test will make it easier to differentiate the binder options

\section{RESULTS AND DISCUSSION}

\section{Effect of GP Type (Color) and Quantity on Workability of High Strength Mortars (HSM)}

Effect of silica fume and glass powder on the workability of mortars at different $\mathrm{w} / \mathrm{b}$ ratios were investigated and results were illustrated in Fig 4.1. As results depicted, replacement of silica fume decreased the workability of fresh mortar, however glass powder increased it. In addition, comparisons revealed that the type of glass powder has no effect on the workability, while the amount of glass powder replaced is efficient; increased workability of mortars by replacing the glass powder is because of its particle surface. The surface of glass powder particles is smoother than cement particles so less water is required to cover the whole surface of glass particles. As replacement of GP increases, free water in fresh mortar increases consequently and it leads to higher workability

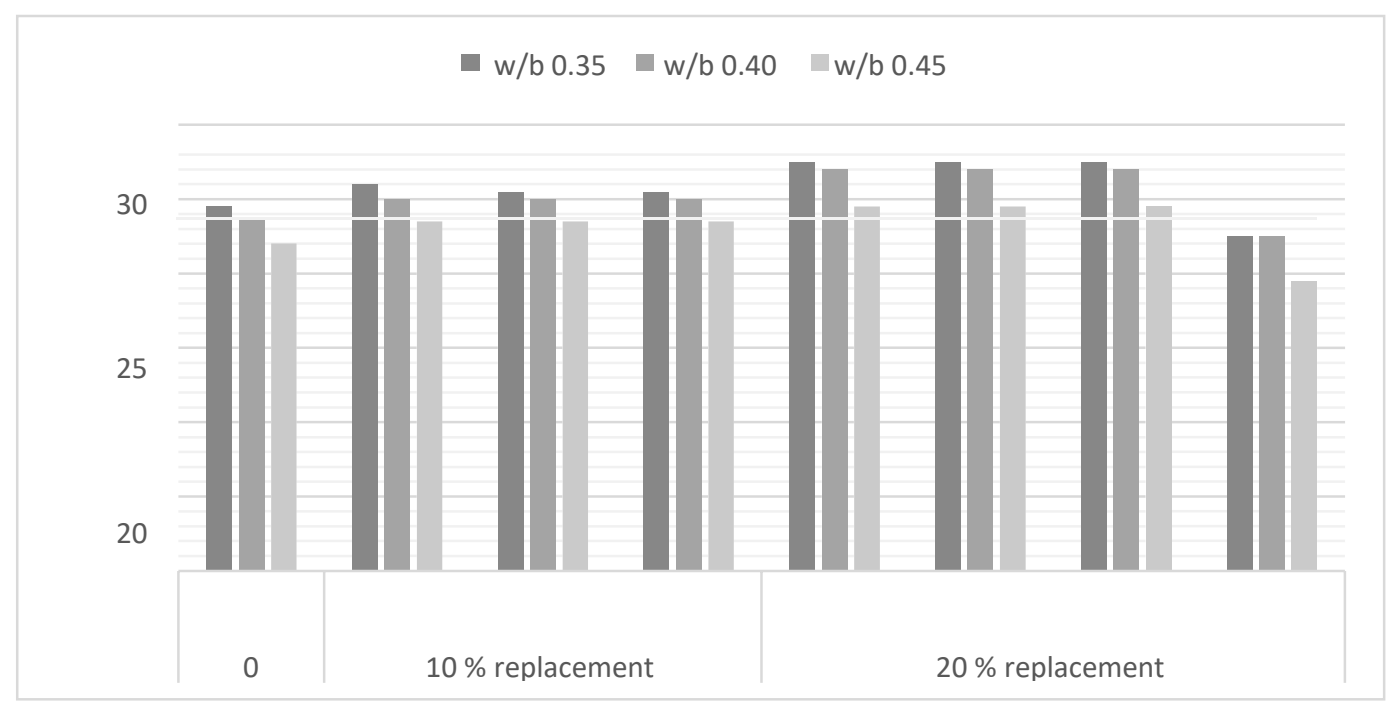

Figure 1: Effect of Different Colors and Quantities of GPs on Workability Relative to Control and SF 


\section{Effect of GP Type and Quantity, w/b Ratio, and Curing Temperature on Compressive Strength of HSM}

The following charts illustrate the compressive strength of mortars prepared at different $w / b$ ratios and different temperatures. The compressive strength of samples prepared in each condition is compared together and with control mix to evaluate the effect of glass powder in different situations.

As it has been shown in Fig 1, at standard temperature and $w / b$ of 0.35 , mortars that modified with different types of glass powder expressed

lower compressive strength at the early age, comparing to control mi

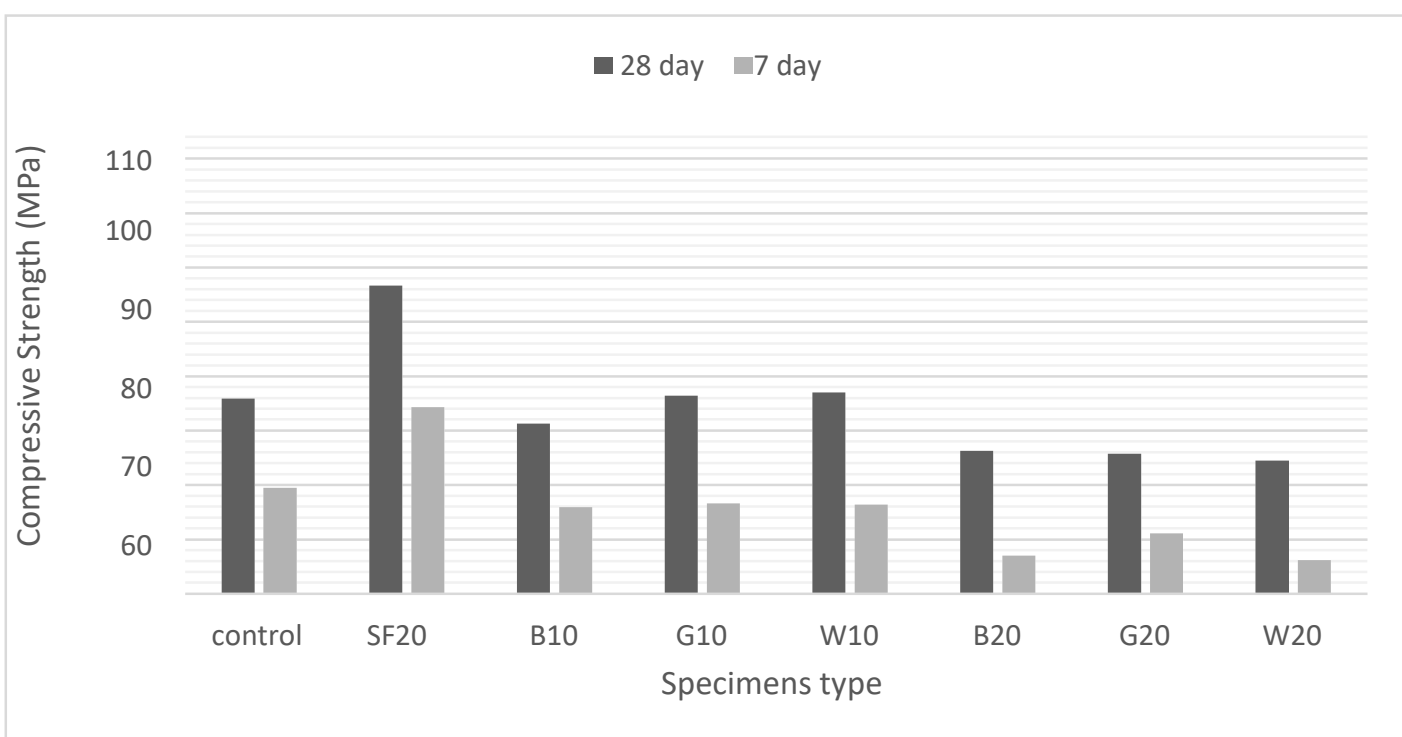

Figure 2: Effect of Different Colors and Quantities of GPs on 7 and 28 Days Compressive Strengths for w/b 0.35 and $22^{\circ} \mathrm{C}$ Curing Temperature

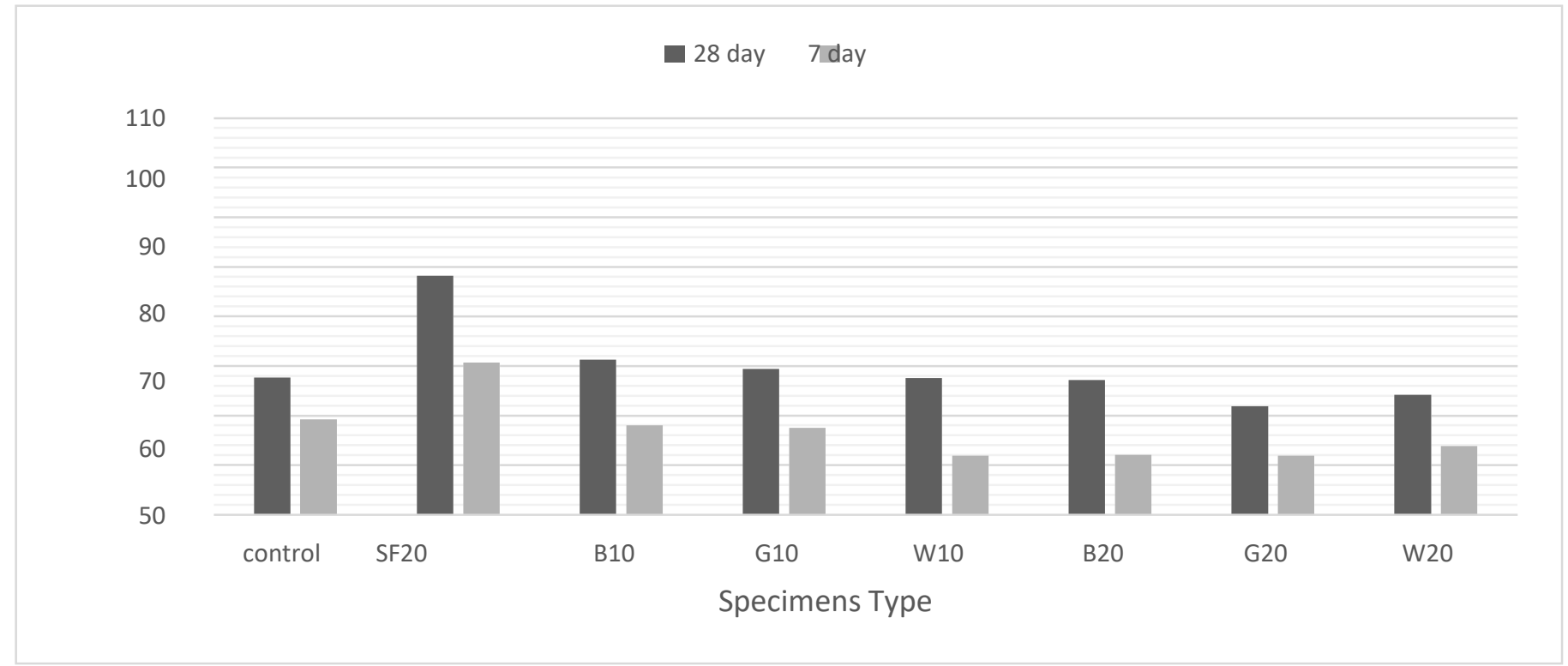

Figure 3 : Effect of Different Colors and Quantities of GPs on 7 and 28 Days Compressive Strengths for w/b 0.40 under $22^{\circ} \mathrm{C}$ Curing Temperature. 


\section{8 day 7 day}

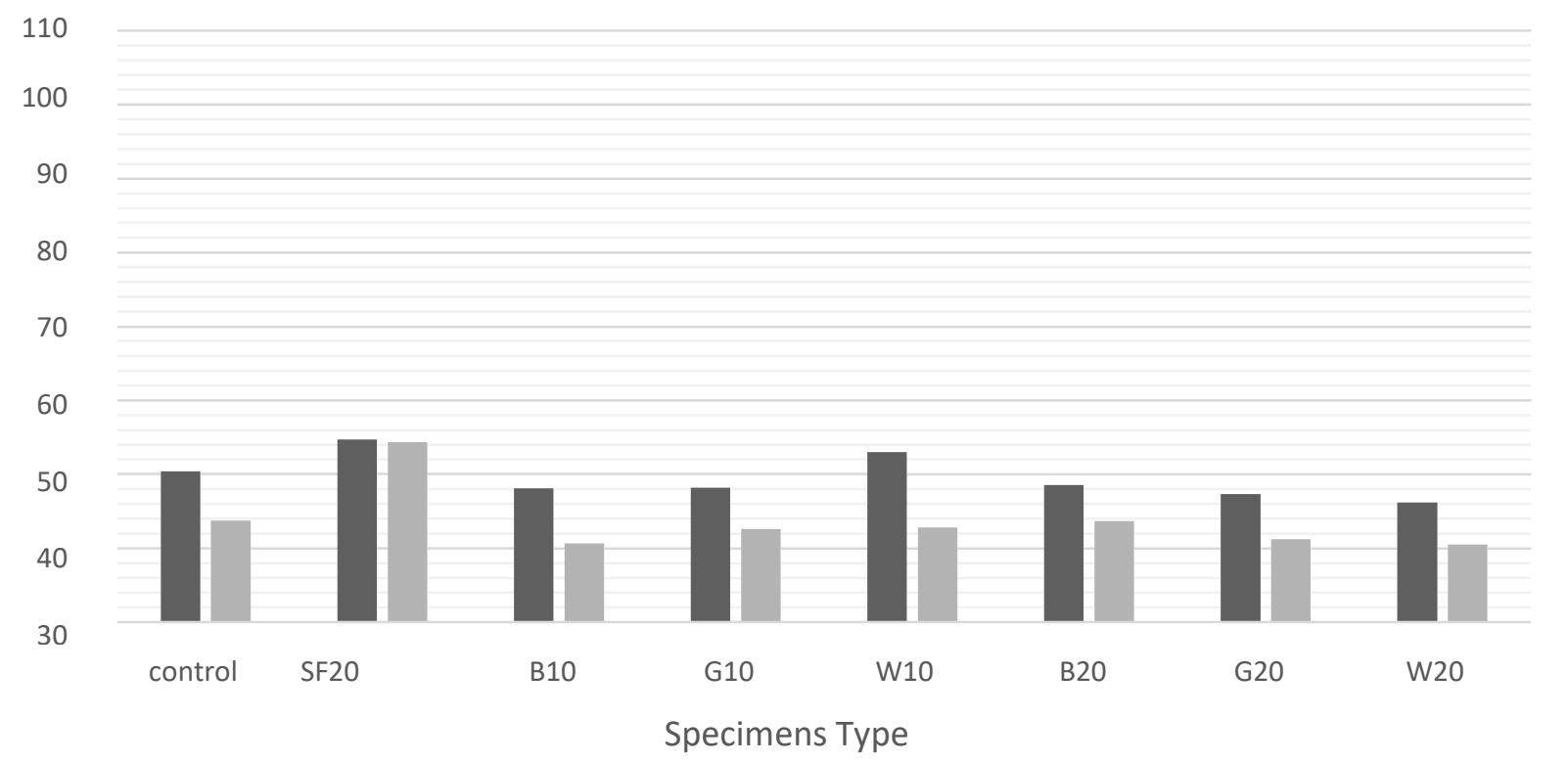

Figure 4 : Effect of Different Colors and Quantities of GPs on 7 And 28 Days Compressive Strengths for w/b 0.40 under $55^{\circ} \mathrm{C}$ Curing Temperature

At early ages, in figure 3 the compressive strength of all mortars except SF20 was lower than control, while the compressive strength of B10, G10 and W10 become slightly higher. In conclusion, the replacement of glass powders decreased the rate of hydration at normal curing temperature.

As it is illustrated in Fig 4, the compressive strength is almost the same for control mix and other mixtures, which are modified by GP at curing temperature of $55^{\circ} \mathrm{C}$ in early ages. However, W10 showed slightly higher compressive strength, but the rest of mortars modified with glass powder depicted lower amount in compressive strength at later ages. It can be seen that, SF20 did not obtain higher compressive strength after the 7th day.

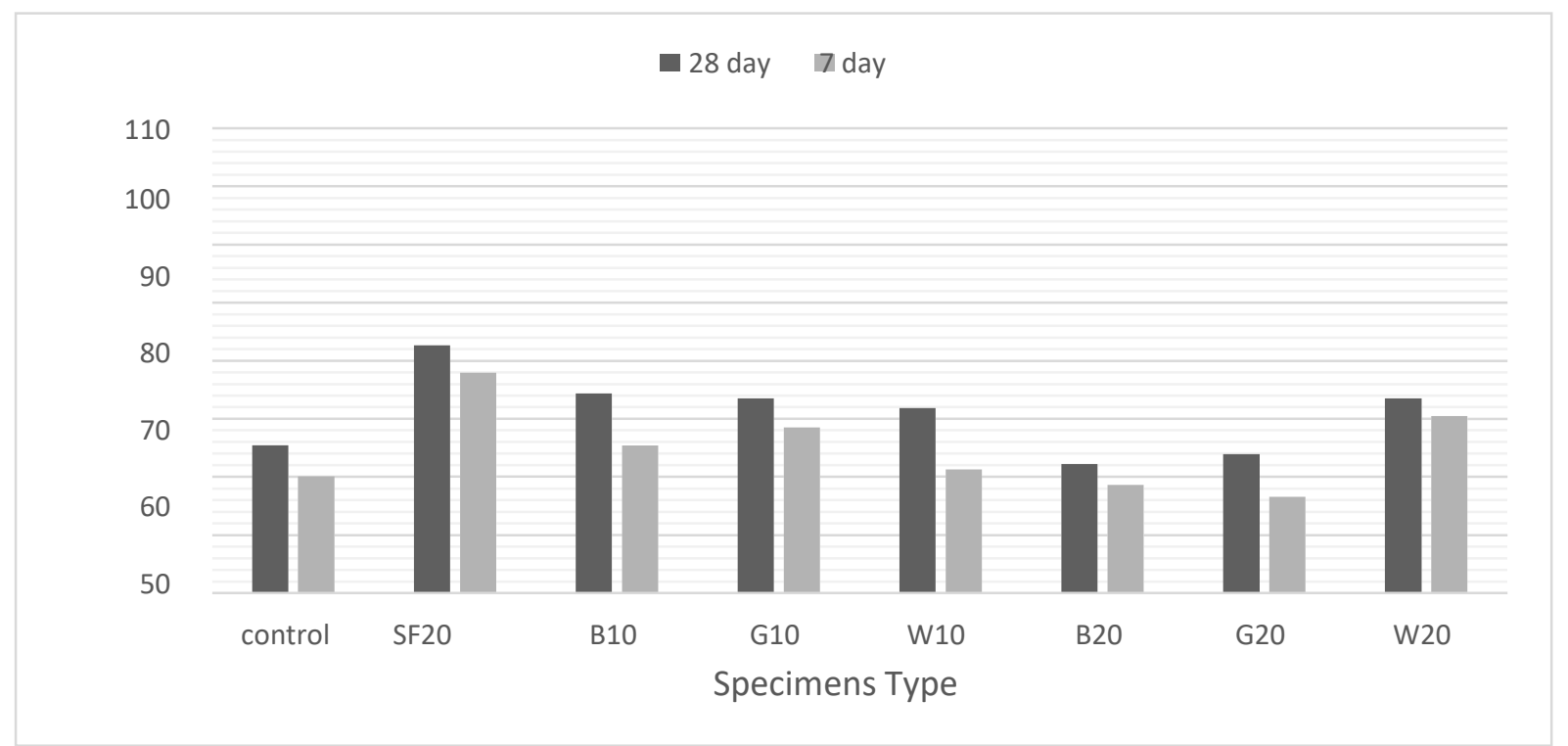

Figure 5 : Effect of Different Colors and Quantities of GPs on 7 and 28 Days Compressive Strengths for w/b 0.40 under $80^{\circ} \mathrm{C}$ Curing Temperature.

The comparison between all specimens that prepared at w/b of 0.40 and different curing temperatures showed that, early compressive strength of control mixture decreases as the temperature increases to $55^{\circ} \mathrm{C}$ then increases when the temperature raises again to $80^{\circ} \mathrm{C}$. This process is valid for SF20, B10, G10, G20, and W20. But the Compressive 
strength of B20 and $\mathrm{W} 10$ increased as the temperature increased without any drop at $55^{\circ} \mathrm{C}$ as it is illustrated in Fig 4.10. In this range, the increase in rate of compressive strength related to samples modified with glass powder due to elevated temperatures was more than control mixes.

\section{Rapid Chloride Permeability}

Rapid chloride permeability test is performed on brown glass powder at different proportions, normal curing condition and fixed $w / b$ ratio of 0.45 . Results of RCPT showed that, the resistance of mortars modified with GP toward ionic penetration is increased as the amount of GP increased up to $10 \%$ and it is compared with control mix which is enlisted in table 4.1. However increasing the amount of GP from $10 \%$ to $20 \%$ decreased the resistance of mortar against chloride ions penetration. Generally, more amount of glass powder benefits the resistance of mortars toward ionic penetration. The reason can be found in glass powder particles size, which is smaller than cement particles and fills empty voids. With respect to pozzolanic reactivity of glass powder, the production of C-S-H components in the paste of mortar increased which filled empty voids due to expansion nature of $\mathrm{C}-\mathrm{S}-\mathrm{H}$ within production and decreased the permeability of mortars. It should be noted that, the amount of coulombs passed from SF20 was the lowest among the rest samples.

\section{Pozzolanic Activity Index of Glass Powders}

According to ASTM standard tests, pozzolanic /strength activity index of all glass powders and silica fume is investigated in this study to see whether all three types of GP are approved or not. The strength activity index of all samples compared and results are shown in Fig 4.50. Obviously, the strength activity of silica fume was higher than control mix and all other specimens. On the other hand, activity index of GPs was lower than control mix as they gained the minimum amount of activity index of $75 \%$, however all three samples are acceptable by ASTM standard. Comparison among all three samples that containing glass powder indicated that, the GGP and BGP exhibited highest and lowest strength activity index respectively.

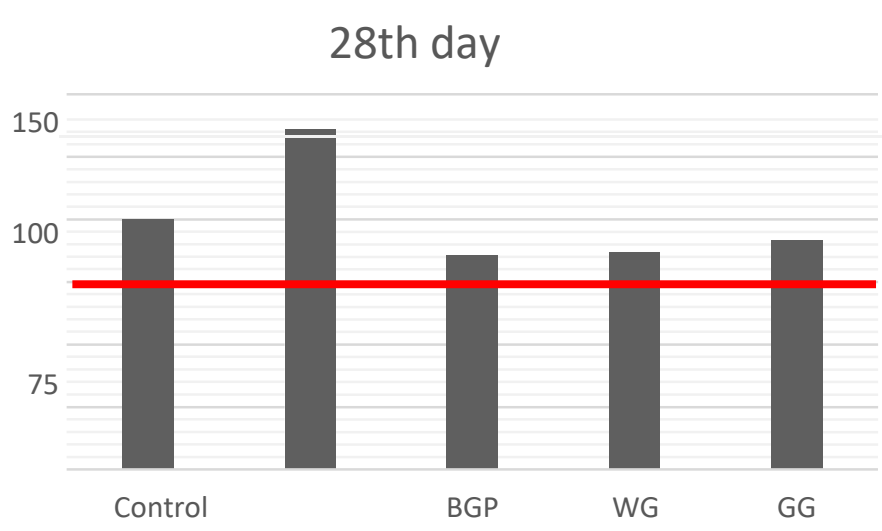

Figure: 6 Strength Activity Index of GPs and SF at the Age of 28 Day

\section{CONCLUSION AND FUTURE SCOPE}

1. Replacement of all types (colors) of glass powder, with quantities varying from $10 \%$ to $20 \%$ increased the workability. On the other hand, both the control and SF specimens showed lower workability than the glass powder ones. Silica fumes achieving the lowest workability.

2. Pozzolanic reactivity of glass powder increases with increase in curing temperature and decreases with increase in $w / b$ ratio.

3. The lower the $w / b$ ratio and the higher the curing temperature, the higher is the 7 th day and 28th day compressive strength. This condition is more obvious at 28 days compressive strength.

4. The pozzolanic reactivity of all modified mortars with SF and GPs increased as the curing temperature increased.

5. Raisin the temperature increased the rate of hydration and accelerates the pozzolanic reaction of SF and GP pozzolans.

6. The value of young's modulus of mortars modified with all types and quantities of glass powders is close to the values of the control under $22{ }^{\circ} \mathrm{C}$ but lower than control at $55^{\circ} \mathrm{C}$ curing temperature.

7. Strength Activity index of GPs was lower than control mix. However all three samples are acceptable by ASTM standard as they gained the minimum amount of activity index of $75 \%$. In addition, comparison between all three samples that contained glass powder indicated that, the GGP and BGP exhibited highest and lowest strength activity index respectively.

8. The resistance of mortars modified with GP towards ionic penetration is increased when $10 \%$ of GP is used (comparing with control mix). However increasing the amount of GP from $10 \%$ to $20 \%$ decreased the resistance of mortar against chloride ions penetration.

\section{RECOMMENDATIONS}

1. Further experiments by using different quantities of glass powder could be examined with different w/b ratios for normal and low strength mortars.

2. Effects of glass powders could be examined for longer ages than 28 days and curing temperature.

\section{REFERENCES}

[1] Aboshama, A. A. (2016). Utilization of waste glass powder in the production of cement and concrete. Construction and Building Materials, 124, 866-877.

[2] Miguel Ángel Sanjuán, C. A. (2015). Effect of silica fume fineness on the improvement of Portland cement strength performance. Construction and Building Materials, 96, 55-64.

[3] Ismail Ansari, S. S. (2015). Utilization Of Glass Powder As A Partial Replacement Of Cement And Its Effect On Concrete Strength. IRF International Conference, 1-5.

[4] Jos Olivier, G. J.-M. (2015). Trends in global CO2 emissions. Den Haag: PBL Publishers.

[5] Kumarappan, N. (2013). Partial replacement cement in concrete using waste glass Eng. Res. Technol, 10(2), 34-41. 
[6] Dali, J. S. (2012). Performance of concrete containing mineral admixtures subjected to high temperature. 37th Conference on Our World in Concrete and Structures Singapore.

[7] Chikhalikar, S. (2012). An experimental investigation on characteristics properties of fibre reinforced concrete containing waste glass powder as pozzolan. 37th Conference on Our World in Concrete and Structures. Singapore

[8] Shayan, A. X. (2006). Performance of glass powder as a pozzolanic material inconcrete: a field trial on concrete slabs. Cement concrete research, 24(5), 457-68. 